\title{
Role of Nigella sativa seed oil on corneal injury induced by formaldehyde in adult male albino rats
}

\author{
N.A. Salem ${ }^{1}$, O.M. Mahmoud ${ }^{1}$, M.H. Al Badawi ${ }^{1}$, A.A. Gab-Alla ${ }^{2}$ \\ ${ }^{1}$ Department of Anatomy, Faculty of Medicine, Suez Canal University, Ismailia, Egypt \\ 2Department of Ophthalmology, Faculty of Medicine, Suez Canal University, Ismailia, Egypt
}

[Received: 9 December 2015; Accepted: 2 January 2016]

\begin{abstract}
Formaldehyde is frequently used in occupational environments, its toxicity concerns to all who work closely with it such as anatomists. Nigella sativa is an amazing herb with a rich historical and religious background; its seeds are the source of its active ingredients. The purpose of the present study was to evaluate the role of Nigella sativa oil on corneal injury induced by formaldehyde in adult male albino rats. Forty adult male albino rats were divided randomly to four groups 10 rats each: I - Control group, II - Formaldehyde exposed group, III Nigella sativa oil group (40 mg/kg/day) via intragastric tube daily for 2 weeks and IV - Formaldehyde and Nigella sativa group. Rats were sacrificed with ether, the corneas were extracted, one processed for haematoxylin and eosin stain and the other was used for transmission electron microscopic examination. Our results in group II revealed marked disorganisation, erosion, vacuolation and necrosis of epithelial cells with loss of parts of epithelial layer. Large congested invasion of blood vessels with separation and disorganisation of stromal fibrils. The corneas of group IV showed intact layers of epithelial cells with appearance close to control group. Star shaped cells (limbal stem cells) were obviously noticed in basal and intermediate layer with intact Bowman's membrane. Stroma showed regular parallel collagen, limbal stem cells were also noticed in group III. We concluded that Nigella sativa oil can ameliorate the toxic changes of formaldehyde on rat corneas. (Folia Morphol 2016; 75, 4: 518-526)
\end{abstract}

Key words: formaldehyde, Nigella sativa seed oil, cornea, rat

\section{INTRODUCTION}

Formaldehyde (FA) is an organic carbon compound frequently used in occupational and indoor environments [25]. The toxicity of FA is of concern to all who work closely with it such as embalmers, anatomists, histology technicians and medical students [14], in occupational environments (hospitals, textiles, paper, resins, wood composites and in house indoor environments in insulating materials, fabrics, cooking emissions, chipboard) [25]. Acute FA exposure mainly produces mucosal irritation of the eye and upper respiratory tract in human [39].The toxicity involved chromosome damage, oxidative stress, modified proteins and cellular apoptosis [34]. The integrity and functionality of the epithelium plays a key role in refraction of light on the retina. Like other epithelia, the epithelium of the cornea is maintained by stem cells. It has no blood supply, unmyelinated

Address for correspondence: Dr O.M. Mahmoud, Faculty of Medicine, Suez Canal University, Ismailia, Egypt, Zip code: 41111, tel: 0020-01272759000, e-mail: omima34@hotmail.com 
nerve endings that are sensitive to chemicals, temperature and touch [24]. Among the promising medicinal plants, Nigella sativa is an amazing herb with a rich historical and religious background; its seeds are the source of the active ingredients of this plant [9]. The best seeds come from Egypt where they grow under almost perfect conditions commonly known as black seed or black cumin and are used as herbal medicine all over the world [4]. Nigella sativa seeds mainly contain thymoquinone (TQ), dithymoquinone (DTQ), thymohydroquinone (THQ), and thymol (THY) [8]. Seeds and its oil have shown beneficial therapeutic effects, including anti-oxidant, anti-inflammatory, anti-cancer, anti-microbial, and immunomodulatory effects [13].

\section{MATERIALS AND METHODS}

\section{Animals}

Forty adult male albino rats (weighing 150-200 g) were obtained from the animal house of the Faculty of Medicine, Ain Shams University. Rats were left at the experimental animal house for 2 weeks to allow them to acclimatise to the new environment and housed in spacious wire mesh cages in a good ventilated room at room temperature and humidity with free access to water and food on balanced diet.

The animals were divided randomly into four groups, 10 rats each:

I. Control group: The animals received $2 \mathrm{~mL}$ sterile distilled water daily via intragastric tube for 2 weeks ( 5 days in week);

II. Formaldehyde exposed group: Rats subjected to FA inhalation released from a cotton piece soaked with $10 \% \mathrm{FA}$ and placed in a small glass box inside the cages and placed far from the rats by a distance of $15 \mathrm{~cm}$, the duration time of exposure was $2 \mathrm{~h}$ per day for 2 weeks ( 5 days in week). At non-exposure times all groups of animals were kept in the laboratory animal quarters, which were far from the FA exposure place;

III. Nigella sativa oil group: The animals received $(40 \mathrm{mg} / \mathrm{kg} /$ day) daily via intragastric tube for 2 weeks (5 days in week), (Baraka 450 mg capsules, Pharco pharmaceuticals, Alexandria, Egypt) [16];

IV. Formaldehyde and Nigella sativa oil group: The animals exposed to FA and received Nigella sativa oil as previous groups.

The current study was performed in the Medical Research Centre, Faculty of Medicine, Ain Shams Uni- versity. At the end of experiment, each rat of the four experimental groups were sacrificed with ether, the eyes were enucleated and the corneas were extracted by circumferential excision $2 \mathrm{~mm}$ posterior to corneoscleral junction. One was processed for paraffin sections for haematoxylin and eosin stain. The other was used for transmission electron microscopic study. The tissue specimens were cut into very small sections and were fixed in buffered $2.5 \%$ glutaraldehyde for $2 \mathrm{~h}$ and post-fixed in $1 \%$ osmic tetroxide for electron microscopic studies. Semithin sections were prepared and stained with toluidine blue. Ultrathin sections were stained using a double-staining technique of uranyl acetate and lead citrate solutions to be examined under an electron microscope.

\section{Ethical consideration}

All experiments were carried out in accordance with the guidelines of Institutional Animals Ethics Committee of Suez Canal University.

\section{RESULTS}

\section{Control group}

Examination of corneal section revealed that the cornea consists of 5 layers: the surface epithelium, Bowman's membrane, the stroma which forms the major part of the cornea, Descemet's membrane, and the endothelium. The corneal epithelium consists of flattened superficial cells, wing cells, and a single layer of columnar basal cells. Beneath the corneal epithelium lies the Bowman's membrane. Corneal stroma is made of regularly arranged collagen fibrils contains keratocytes, fibroblast like cells. The noncellular Descemet's membrane located between the stroma and the internal endothelium. The corneal endothelium consists of a single layer of polygonal flattened cells (Figs. 1, 2, 3).

\section{Formaldehyde group}

Examination of corneal section showed disorganisation, erosion, vacuolation and necrosis of epithelial cells with loss of some parts of epithelial layer and oedema of its cells. Absence of the Bowman's membrane, invasion of large congested blood vessels were noted with separation and disorganisation of stromal fibrils was also seen (Fig. 4).

An electron photomicrograph showed areas of complete loss of epithelial layers, swelling of basal layer with vacuolation of its cytoplasm. Central clumping of chro- 


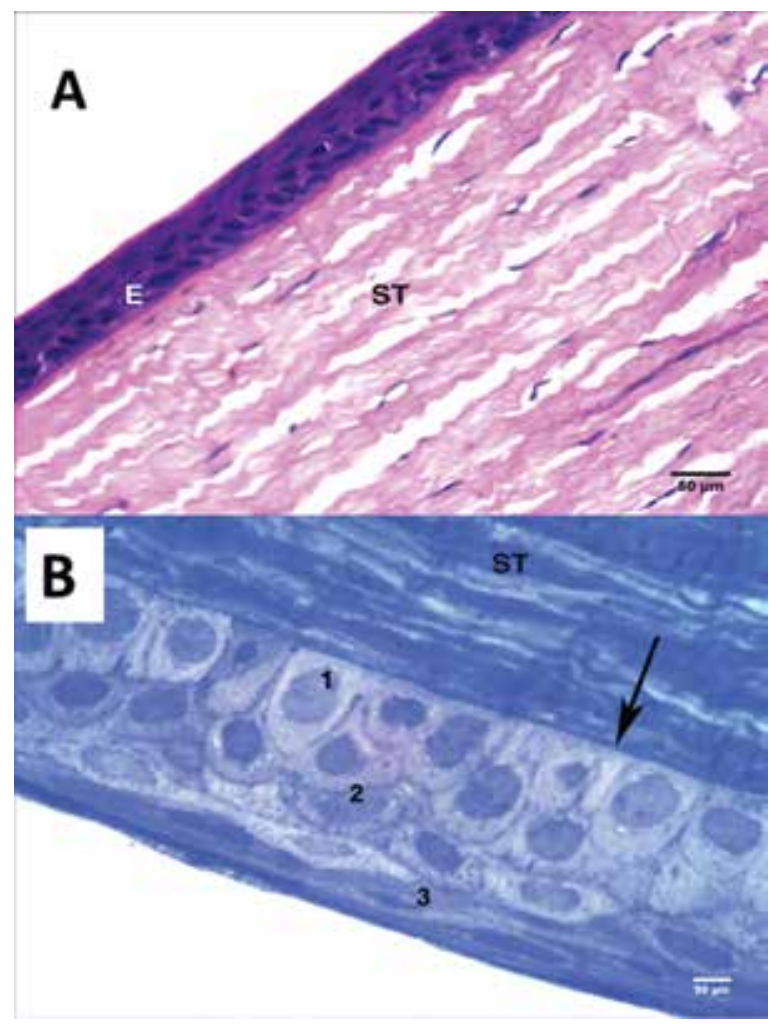

Figure 1. A photomicrograph of rat cornea of control group showing intact epithelium (E) with its basal columnar cells (1), intermediate wing cells (2), and superficial flat squamous cells (3). The epithelium is supported by Bowman's membrane (arrow) and the stroma (ST) contains regular parallel collagen lamellae and stromal cells; A. Haematoxylin and eosin $\times 400$; B. Toluidine blue $\times 1000$. matin in its nucleus, disorganisation of the chromatin in intermediate epithelial layer was noticed. Following abnormalities were also observed: disorganised collagen fibrils with focal areas of separation in corneal stroma; shrunken and severely damaged keratocytes with cytoplasmic vacuolation and irregular nuclear membrane; homogenous Descemet's membrane, vacuolated and detached endothelial cells (Figs. 5, 6, 7).

\section{Formaldehyde and Nigella sativa group}

Examination of corneal section showed intact layers of epithelial cells with appearance close to control group. Star shaped cells (limbal stem cells) were obviously noticed in basal and intermediate layer with intact Bowman's membrane. Stroma showed regular parallel collagen laminae. An electron photomicrograph showed quite normal appearance of epithelial cells with slight vacuolation in its cytoplasm. Stroma showed parallel collagen fibrils with normal keratocytes, homogeneous Descemet's membrane and normal endothelial cell (Fig. 8, 9).

\section{Nigella sativa group}

Examination of this group revealed the same histologic structure as found in the control group with obvious appearance of limbal stem cells, although no corneal injury was observed (Fig. 10).
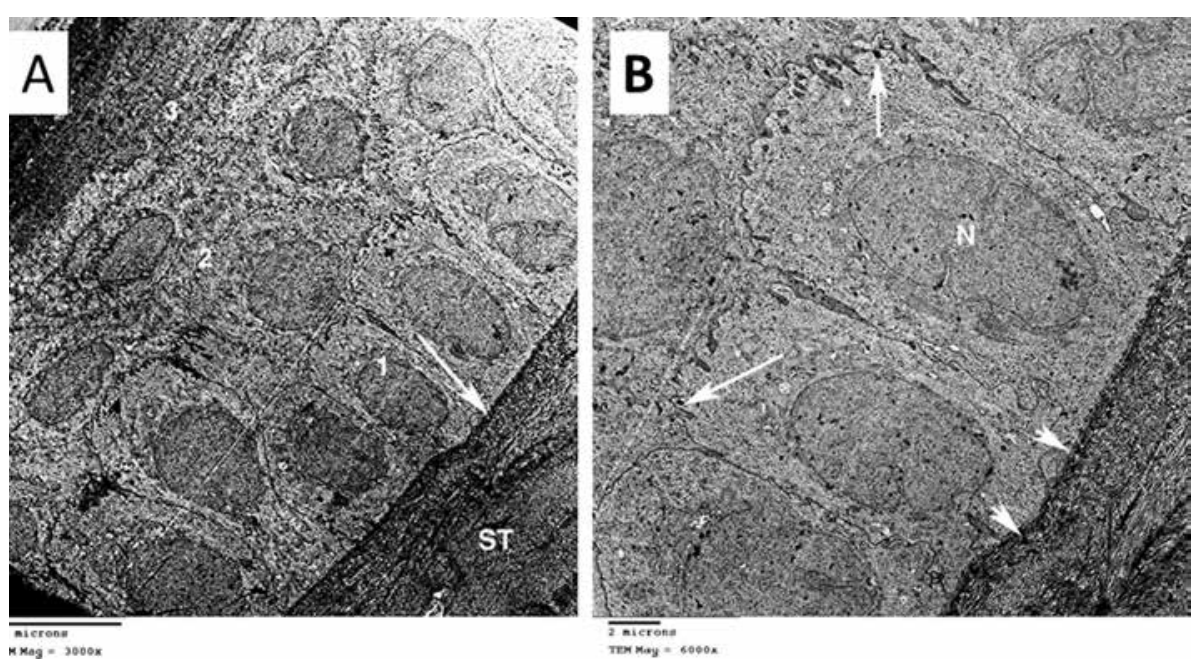

Figure 2. An electron photomicrograph of rat cornea of control group showing (A) intact epithelium with its basal columnar cells (1), intermediate wing cells (2), and superficial flat squamous cells (3). The epithelium is supported by Bowman's membrane (arrow). The stroma (ST) contains regular parallel collagen lamellae; Uranyl acetate and lead citrate $\times 3000$; B. Basal columnar cell containing an oval euchromatic nucleus (N) attached to the basal lamina with numerous hemidesmosomes (arrowhead) and the cells are attached to each other with numerous desmosomes (arrow); Uranyl acetate and lead citrate $\times 6000$. 

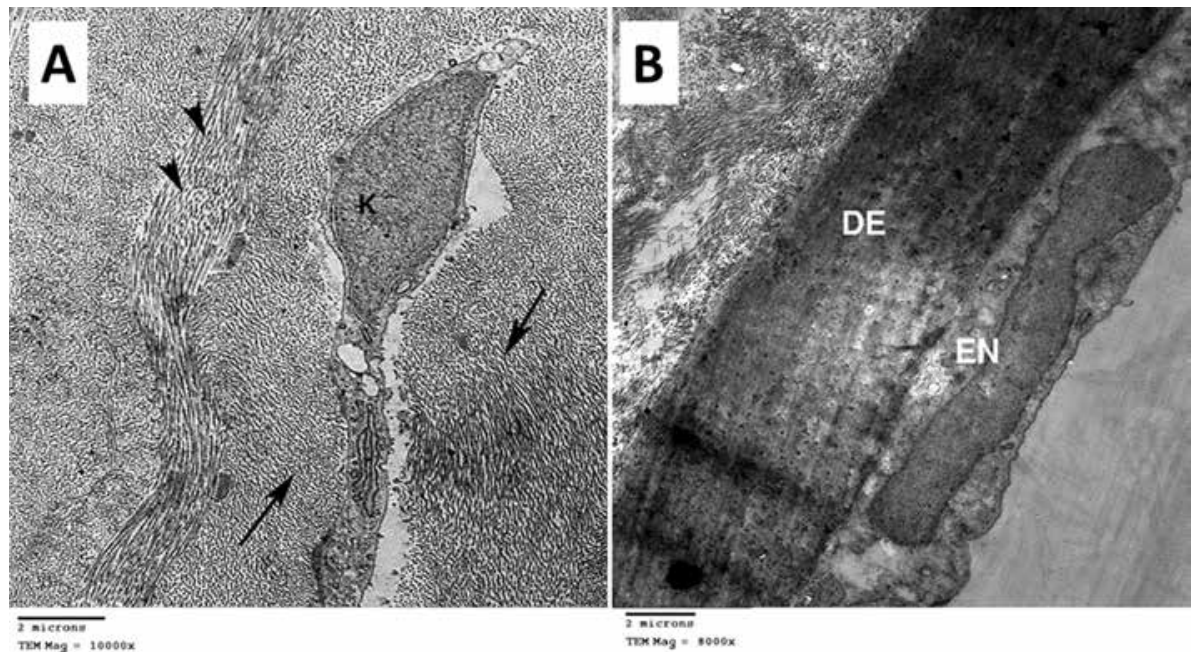

Figure 3. An electron photomicrograph of rat cornea of control group showing (A) keratocytes (K) that appear as spindle shaped cells with large oval nucleus, regular stromal collagen fibrils arranged in transverse (arrow) and longitudinal (arrowhead) arrangement; Uranyl acetate and lead citrate $\times 10000$; B. Normal flattened endothelial cell (EN) resting on homogenous Descemet's membrane (DE); Uranyl acetate and lead citrate $\times 8000$.

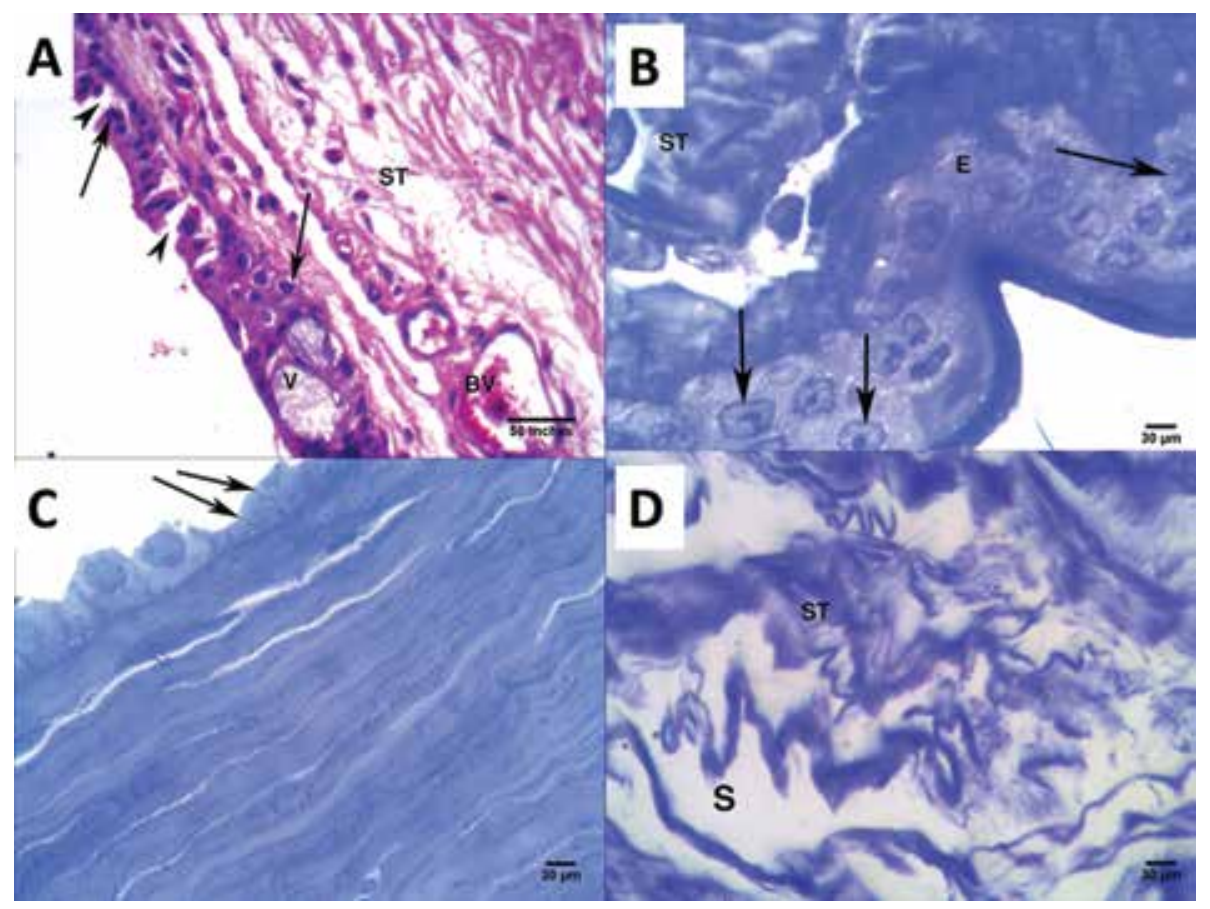

Figure 4. A photomicrograph of rat cornea of formaldehyde group showing (A) erosion (arrow head), vacuolation (V) and necrosis (arrow) of the epithelial cells, absence of the Bowman's membrane, large congestion of blood vessel (BV), separation and disorganisation of stromal fibrils (ST) (haematoxylin and eosin $\times 400$ ); B. Irregular epithelial surface with disorganised epithelial cells (E). Fragmented chromatin (arrow); C. Loss of epithelial layer (arrow); D. Disorganisation and separation (S) of corneal stroma (ST) (B, C, D: toluidine blue $\times 1000$ ).

\section{DISCUSSION}

Formaldehyde commonly used in anatomy laboratory and is classified as carcinogen [34]. Drastic injury to the eye tissue was noticed when studied using direct contact with $37 \%$ FA [15]. The most experimental models widely used were rats and mice, due to their ease of manipulation and low cost. Rodent models lend further support that they were of potential human health risk. Rat had similar response to inflammation and infection as human [10]. In order to establish an animal model for eye research, we used rat eye and the chemical FA to examine corneal injury. 

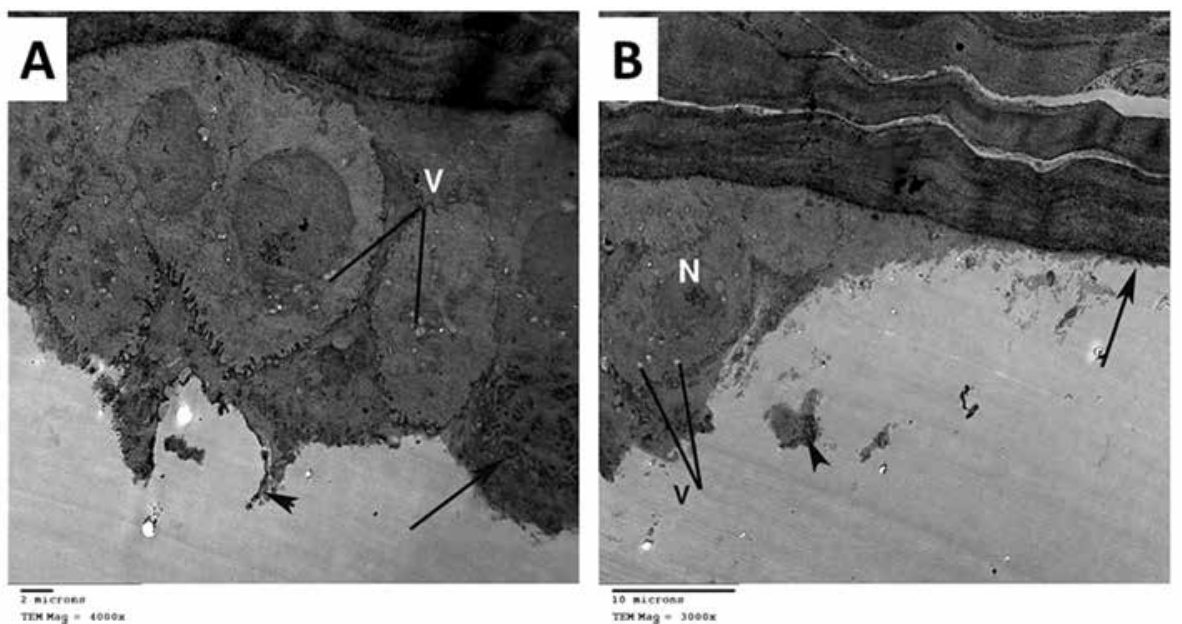

Figure 5. An electron photomicrograph of rat cornea of formaldehyde group showing (A) loss of superficial epithelial layer (arrow head), swelling of the basal layer cells with vacuolation of its cytoplasm (V). Notice disorganization of the chromatin in intermediate epithelial layer (arrow); uranyl acetate and lead citrate $\times 4000$; B. Area of complete loss of epithelial layer (arrow), swelling of basal layer with vacuolation of its cytoplasm (V) and central clumping of chromatin in its nucleus (N). Notice detached part of epithelial cell (arrow head); uranyl acetate and lead citrate $\times 3000$ ).

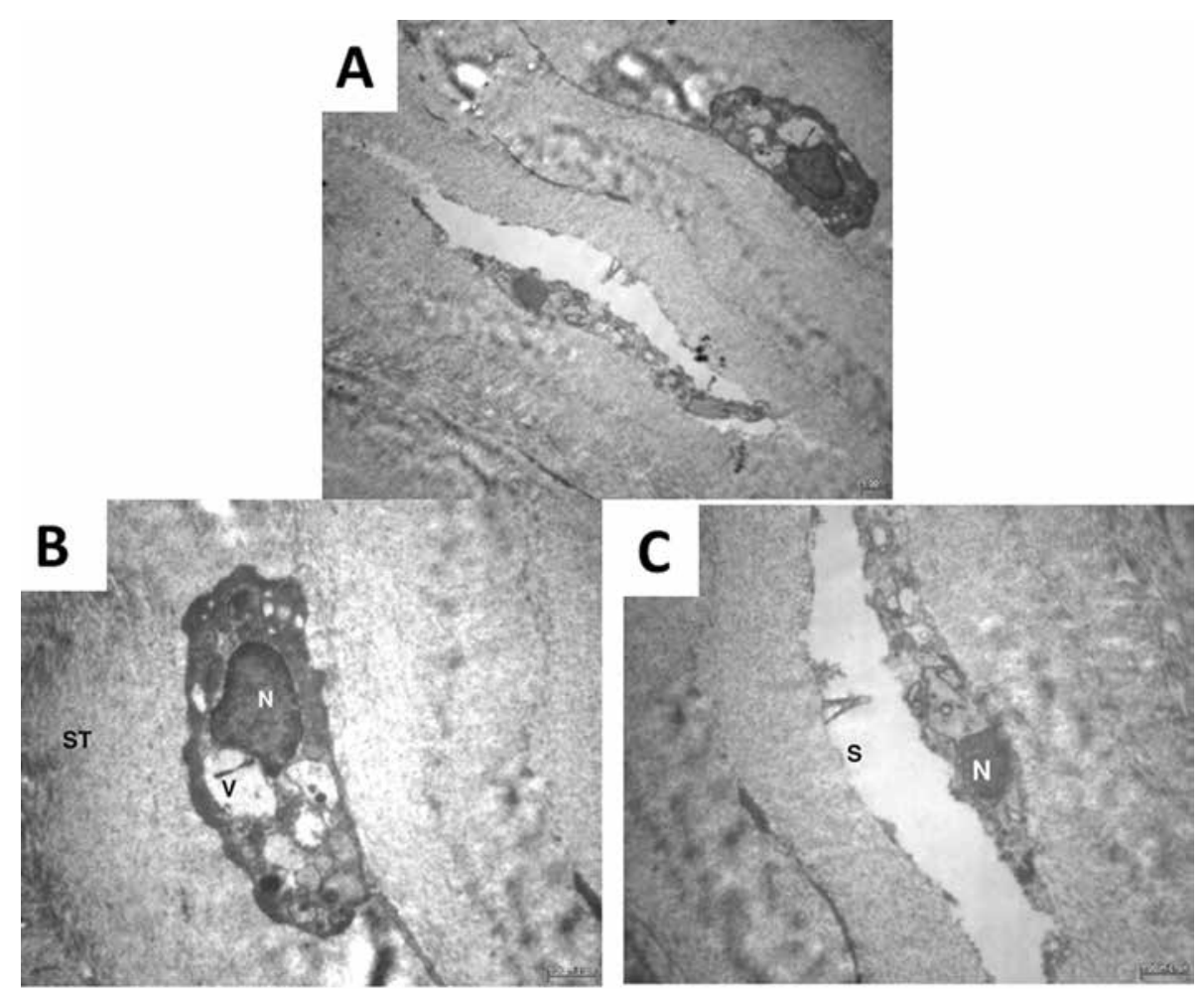

Figure 6. An electron photomicrograph of rat cornea of formaldehyde group showing disorganised collagen fibrils of corneal stroma (ST) with focal area of separation (S). Severely damaged keratocyte with shrunken nucleus (N) and irregular nuclear membrane. Cytoplasmic vacuolation $(\mathrm{V})$ was noticed $(A)$; uranyl acetate and lead citrate $\times 3000$; B, C. Magnification of $(A)$; uranyl acetate and lead citrate $\times 6000$.

The organ systems usually affected by FA include the eyes, upper and lower respiratory tract, skin and central nervous system. Irritation of the eyes results in a burning sensation, lacrimation, and conjunctivitis [32].
A subchronic epidemiological study of 38 anatomy class students, who were exposed, on average, for $2 \mathrm{~h}$ per week over 14 weeks, was performed. After class, eye, nose and throat irritation was significantly elevated compared with pre-laboratory session [20]. 

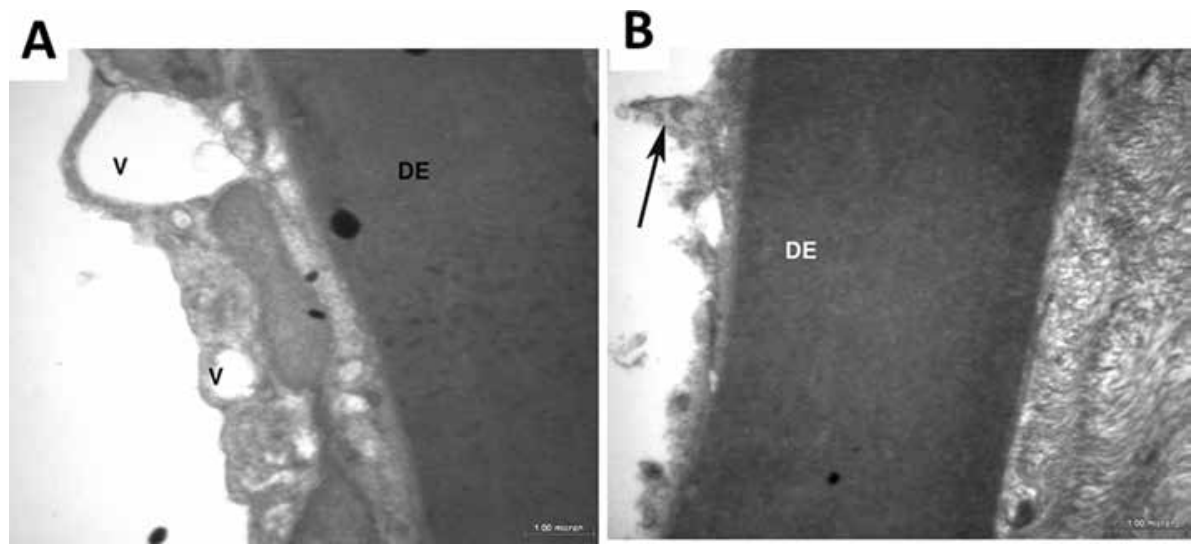

Figure 7. An electron photomicrograph of rat cornea of formaldehyde group showing homogenous Descemet's membrane (DE); $\mathbf{A}$. Vacuolation of endothelial cell cytoplasm (V); B. Detached part of endothelial cell (arrow); uranyl acetate and lead citrate $\times 8000$.

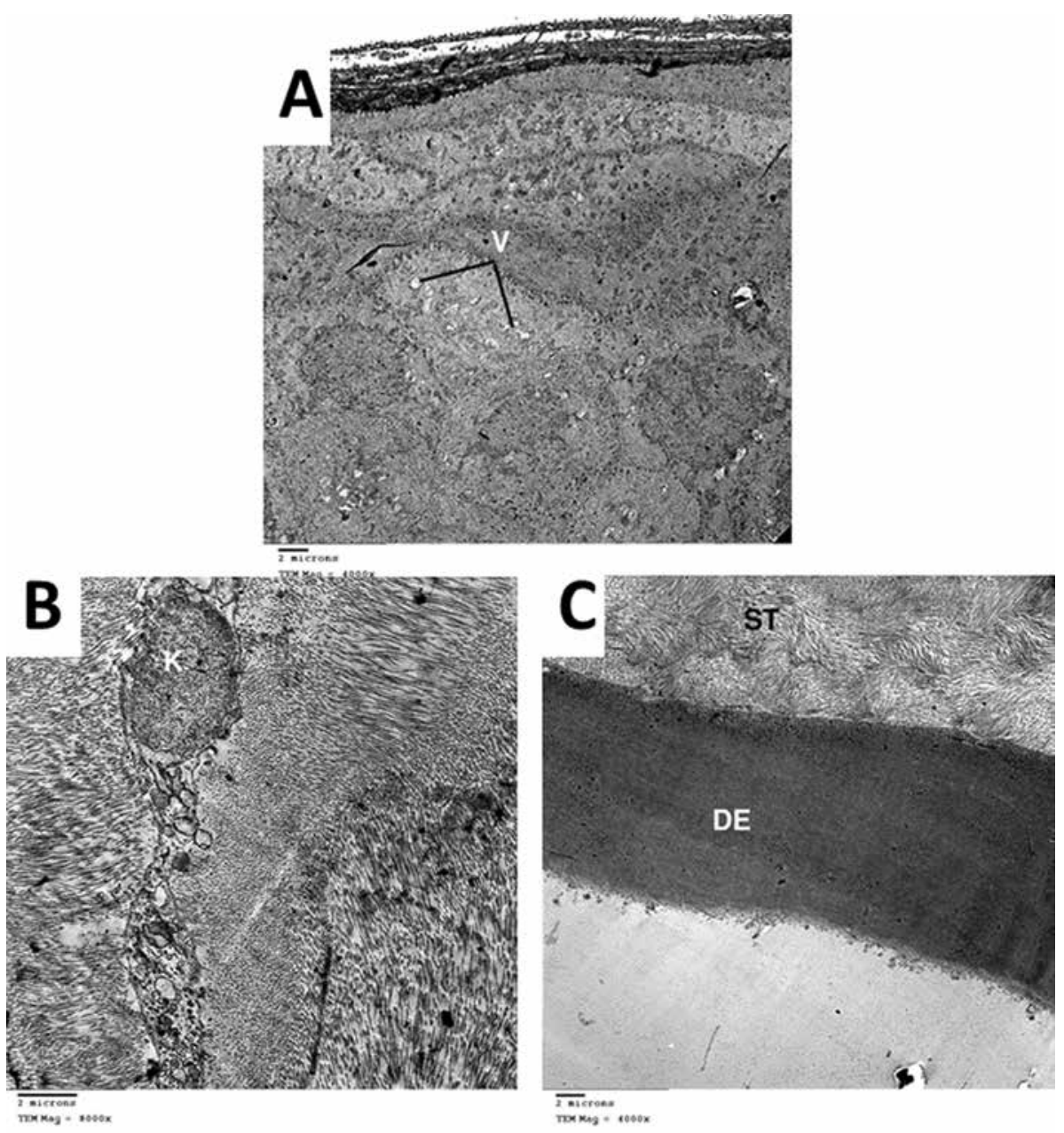

Figure 8. An electron photomicrograph of rat cornea of formaldehyde + Nigella sativa group showing $(\mathbf{A})$ intact intermediate epithelial wing cells and superficial flat squamous cells with some vacuolation (V); uranyl acetate and lead citrate $\times 4000$; B. Regular stromal collagen fibrils and spindle shaped keratocyte $(\mathrm{K})$; uranyl acetate and lead citrate $\times 8000)$; C. A homogenous Descemet's membrane (DE); uranyl acetate and lead citrate $\times 4000$. 


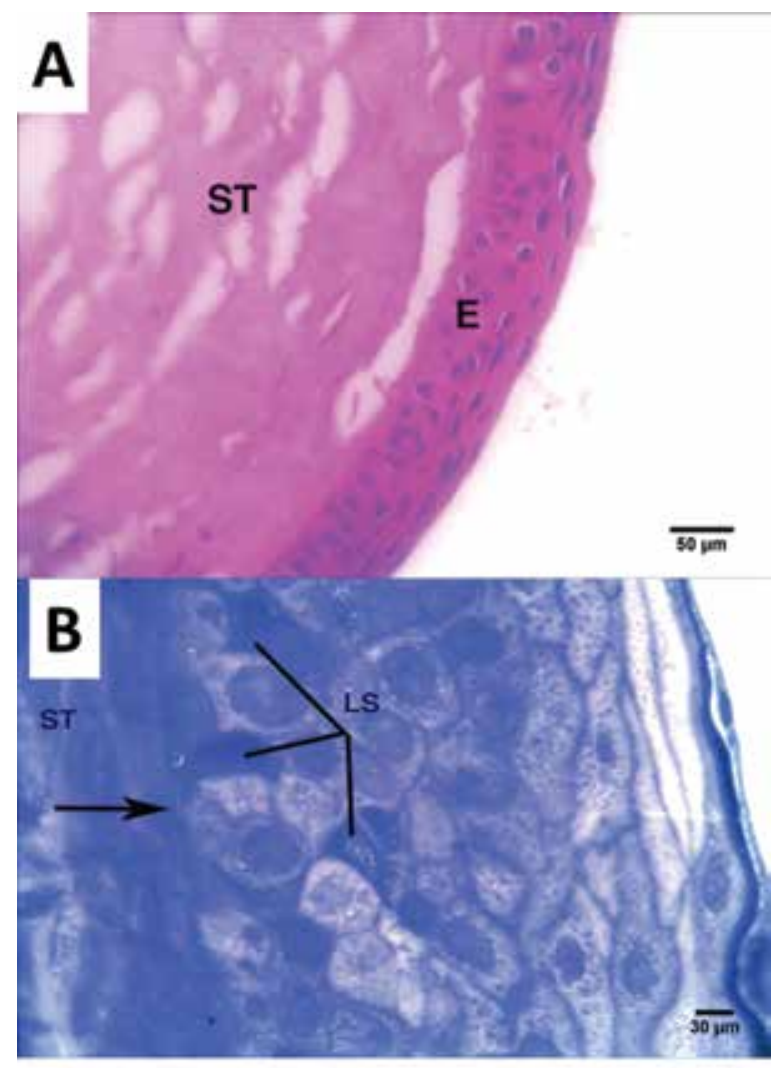

Figure 9. A photomicrograph of rat cornea of formaldehyde + Nigella sativa group showing $(\mathbf{A})$ intact epithelial cells $(\mathrm{E})$. The stroma (ST) contains regular parallel collagen lamellae (haematoxylin and eosin $\times 400$ ); B. Intact epithelial cells supported by Bowman's membrane (arrow). Limbus stem cells (LS) in basal layer of epithelium (toluidine blue $\times 100$ ).

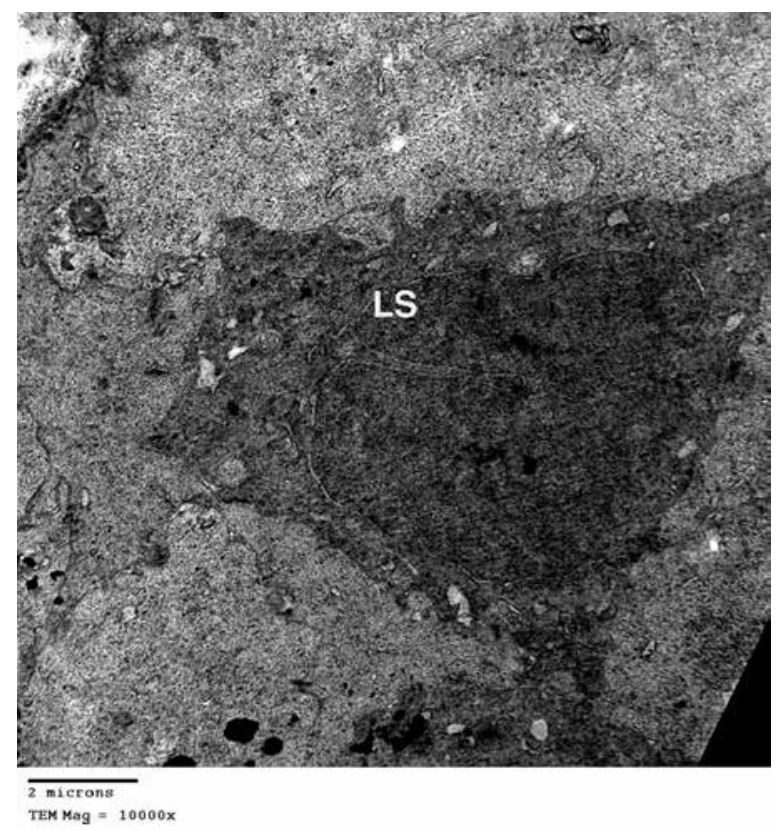

Figure 10. An electron photomicrograph of rat cornea of Nigella sativa group showing appearance of limbal stem cells (LS); uranyl acetate and lead citrate $\times 1000$.
The time of exposure in this study was the same time that we used in our study.

Our results showed areas of complete loss of epithelial layers, swelling of basal layer with vacuolation of its cytoplasm, central clumping of chromatin in its nucleus and necrosis of epithelial cells, disorganisation of the chromatin in intermediate epithelial layer and vacuolation with some detached endothelial cells were noticed. These results agreed with previous studies; FA has been reported to cause DNA damage, thereby leading to apoptosis [28]. Another study found that FA can interact with molecules on cell membranes and fluids in body tissues, which disrupt cellular functions. High concentrations cause precipitation of proteins, which results in cell death, and longer period after exposure the corneal epithelial cells showed abnormal cell count, cell morphology, tear production and apoptosis/necrosis [21]. There was a potential for epithelial cells differentiation into fibroblastic cells in response to morphogenic pressure from injured tissue. The phenomenon is known as epithelial-mesenchymal transition and it can occur in limbal location in rabbit corneal explant [17].

The current model of the stromal reaction to injury encompasses a keratocyte transition from a quiescent state to an activated, migratory, collagen-secreting cell phenotype that is often referred to as a corneal fibroblast. Tissue-cultured keratocytes are generally thought of as being corneal fibroblasts [7]. Abnormal subepithelial fibrosis and epithelial keratinisation, such as severe ocular surface fibrosis, can cause vision impairment [18]. Several inflammatory cytokines may initiate the mechanism of corneal subepithelial fibrosis through corneal stromal fibroblast activation [30]. Transient treatments with FA for $3 \mathrm{~min}$, the corneal epithelial cells were transformed to fibroblastic morphology at 7-day culture [21]. This agreed with our results which revealed disorganisation of collagen fibrils with focal areas of separation in corneal stroma, shrunken keratocytes with cytoplasmic vacuolation and irregular nuclear membrane, absence of the Bowman's membrane, and large congestion of blood vessels.

The histopathological pictures of our results in formaldehyde exposed group resemble the pathological picture of chemical burn of cornea. These results agreed with other study [2] which found that corneal epithelium of basal layer was separated from the stroma and stability of the cornea was disrupted. Corneal ulceration, perforation and neovascularisation 
are the most common acute complications of corneal chemical burns. Some authors found that partial or full limbal epithelial stem cells (LESC) deficiency leads to deleterious effects on corneal surface integrity following injuries including chemical or thermal burns [5]. At the corneo-scleral junction, there is a population of LESCs that are a major renewable source of epithelial cells from the cornea [27]. Corneal integrity and function is dependent upon the self-renewing properties of the corneal epithelium [36]. A variety of cytokines have been shown to play important roles in the maintenance and wound healing of the cornea. These factors are supplied in part by the adjacent tear film and the aqueous humour [37]. Other growth factors are produced by keratocytes in the supporting stroma [38] and by the corneal epithelial cells themselves [29].

An important study based on methanol extracts of the shoots and seeds of Nigella sativa were studied regarding inflammatory activities and found that seeds hexane fraction of the methanol extract has significant anti-inflammatory activity [3]. Oral treatment of Nigella sativa also showed a reduction of formalin-induced paw oedema [35].

Our result in treated group with Nigella sativa oil showed intact layers of epithelial cells with appearance close to that of control group. Star shaped cells (limbal stem cells) were obviously noticed in basal and intermediate layer with intact Bowman's membrane; stroma showed regular parallel collagen laminae. These results agreed with another study which found that the presence limbal stem cells were observed as a pigment (melanin) that moved from the limbus towards an epithelial defect following wounding of rabbit corneas [23]. Complete removal of the limbus results in impaired corneal function, neovascularisation and conjunctival ingrowth [12]. Limbal basal cells exhibit higher proliferative potential when compared with peripheral and central cells both in vitro and in vivo [22]. Large epithelial wounds in rabbits heal faster than smaller central defects; which can be explained by the fact that the proliferative capacity of the peripheral cornea is greater than that of the central. In the human, limbal explant cultures have greater proliferative potential when compared with central explants [6].

More than 150 studies conducted since 1959 confirmed the pharmacological effectiveness of Nigella sativa seed constituents. Seed is a complex substance of more than 100 compounds, some of which have not yet been identified or studied [31]. Earlier studies based on animal have shown that Nigella sativa and its constituents (mainly TQ) show a pivotal role in the maintenance of immune system via the suppression or activation of various B-cells, T-cells and cytokines. Earlier finding reported that oil of Nigella sativa and derived TQ inhibit eicosanoid generation in leukocytes and membrane lipid peroxidation [11]. Conversely, a study performed by Khazaei and Salehi [19] showed that Nigella sativa does not seem to have immunomodulatory effect on T-helper 1 and T-helper 2 cells in response to allergen stimulation [19]. Also previous study reported that TQ has cytoprotective effects that are mainly mediated due to its antioxidant and anti-inflammatory activities [26]. The oil and certain active ingredients showed beneficial immunomodulatory properties, augmenting the T-cell and natural killer cell-mediated immune responses [33]. A study based on albino mice observed that extract of nigella showed a significant analgesic and anti-inflammatory effect [1].

We noticed in our work the appearance of limbal stem cells in two Nigella sativa treated groups (formaldehyde + Nigella sativa group and Nigella sativa group) which indicated that Nigella sativa oil may stimulate mobilisation of limbal stem cells even in non-injured group.

Therefore more experimental animal models and clinical trials must be done to explore the specific cellular and molecular targets of Nigella sativa constituents.

\section{CONCLUSIONS}

Our findings suggest that Nigella sativa oil can ameliorate the toxic effect of FA on corneal tissue.

\section{REFERENCES}

1. Bashir MU, Qureshi HJ (2010) Analgesic effect of Nigella sativa seeds extract on experimentally induced pain in albino mice. J Coll Physicians Surg Pak, 20: 464-467.

2. Beyazyıldız E, Alpaslan F, Beyazyıldız O, Beden O, Delibaş T (2012) A modified rat model for corneal alkali burn. Niche, 1: 31-33.

3. Bourgou S, Pichette A, Marzouk B, Legault J (2012) Antioxidant, anti-inflammatory, anticancer and antibacterial activities of extracts from Nigella sativa (black cumin) plant parts. J Food Biochem, 36: 539-546.

4. Chopra RN, Chopra IC, Handa KL, Kapur LD (1982) Indigenous Drugs of India, Academic Publishers; Calcutta, New Delhi, India, p. 582.

5. Dua HS, Joseph A, Shanmuganathan VA, Jones RE (2003). Stem cell differentiation and the effects of deficiency. Eye (Lond), 17: 877-885. 
6. Ebato B, Friend J, Thoft RA (1988).Comparison of limbal and peripheral human corneal epithelium in tissue culture. Invest Ophthalmol Vis Sci, 29, 1533-1537.

7. Fini ME (1999) Keratocyte and fibroblast phenotypes in the repairing cornea. Prog Retin Eye Res, 18: 529-551.

8. Ghosheh OA, Houdi AA, Crooks PA (1999) High performance liquid chromatographic analysis of the pharmacologically active quinones and related compounds in the oil of the black seed (Nigella sativa L.). J Pharm Biomed Anal, 19: 757-762.

9. Goreja WG (2003) Black Seed: Nature's Miracle Remedy. Amazing Herbs Press, New York, NY7.

10. Hoenerhoff MJ, Hong HH, Ton TV, Lahousse SA, Sills RC (2009) A review of the molecular mechanisms of chemically induced neoplasia in rat and mouse models in National Toxicology Program bioassays and their relevance to human cancer. Toxicol Pathol, 37: 835-848.

11. Houghton PJ, Zarka R, de las Heras B, Hoult JR (1995) Fixed oil of Nigella sativa and derived thymoquinone inhibit eicosanoid generation in leukocytes and membrane lipid peroxidation. Planta Med, 61: 33-36.

12. Huang AJ, Tseng SC (1991) Corneal epithelial wound healing in the absence of limbal epithelium. Invest Ophthalmol Vis Sci, 32: 96-105.

13. Huffman MA (2003) Animal self-medication and ethnomedicine: exploration and exploitation of the medicinal properties of plants. Proc Nutr Soc, 62: 371-381.

14. IARC (2006) Formaldehyde, 2-butoxyethanol and 1-tertbutoxypropan- 2-ol.Monogr Eval Carcinog. Risks Hum, $88,1-478$.

15. Jester JV, Li L, Molai A, Maurer JK (2001) Extent of initial corneal injury as a basis for alternative eye irritation tests. Toxicol Vitro, 15: 115-130.

16. Kalus U, Pruss A, Bystron J, Jurecka M, Smekalova A, Lichius JJ, Kiesewetter H (2003) Effect of Nigella sativa (black seed) on subjective feeling in patients with allergic diseases. Phytother Res, 17: 1209-1214.

17. Kawakita T, Espana EM, He H, Li W, Liu CY, Tsenq SC (2005) Intrastromal invasion by limbal epithelial cells is mediated by epithelial-mesenchymal transition activated by air exposure. Am J Pathol, 167: 381-393.

18. Kawashima M, Kawakita T, Satake Y, Higa K, Shimazaki J (2007) Phenotypic study after cultivated limbal epithelial transplantation for limbal stem cell deficiency. Arch Ophthalmol, 125: 1337-1344.

19. Khazaei M, Salehi H (2006) Protective effect of falcaria vulgaris extract on ethanol induced gastric ulcer in rat. Iran J Pharmcol Ther, 5: 43-46.

20. Kriebel D, Myers D, Cheng M, Woskie S, Cocanour B (2001) Short-term effects of formaldehyde on peak expiratory flow and irritant symptoms. Arch Environ Health, 56: 11-18.

21. Lai L-J, Hsu W-H, Wu AM, Wu JH (2013) Ocular injury by transient formaldehyde exposure in a rabbit eye model. PLoS One, 8: e66649.

22. Lavker RM, Sun TT (2003) Epithelial stem cells: the eye provides a vision. Eye, 17: 937-942.

23. Mann I (1944) A study of epithelial regenration in the living eye. Br J Ophthalmol, 28: 26-40.
24. Maurer JK, Molai A, Parker RD, Li LI, Carr GJ, Petroll WM, Cavanagh HD, Jester JV (2001) Pathology of ocular irritation with acetone, cyclohexanol, parafluoroaniline, and formaldehyde in the rabbit low-volume eye test. Toxicol Pathol, 29: 187-199.

25. Nakazawa H, Ikeda H, Yamashita T, Hara I, Kumai Y, Endo G, Endo $Y$ (2005) A case of sick building syndrome in a Japanese office worker. Ind Health, 43: 341-345.

26. Nagi MN, Mansour MA (2000) Protective effect of thymoquinone against doxorubicin-induced cardiotoxicity in rats: a possible mechanism of protection. Pharmacol Res, 41: 283-289.

27. Pellegrini G, Golisano O, Paterna P, Lambiase A, Bonini S, Rama P, De Luca M (1999) Location and clonal analysis of stem cells and their differentiated progeny in the human ocular surface. J Cell Biol, 145: 769-782.

28. Recio L, Sisk S, Pluta L, Bermudez E, Gross EA, Chen Z, Morgan K, Walker C (1992) P53 Mutations in formaldehydeinduced nasal squamous cell carcinomas in rats. Cancer Res, 52: 6113-6116.

29. Rolando M, Zierhut M (2001) The ocular surface and tear film and their dysfunction in dry eye disease. Surv Ophthalmol, 45: S203-S210.

30. Saika S, Yamanaka O, Sumioka T, Miyamoto T, Miyazaki K, Okada Y, Kitano A, Shirai K, Tanaka S, Ikeda K (2008) Fibrotic disorders in the eye: targets of gene therapy. Prog Retin Eye Res, 27: 177-196.

31. Salem ML (2005) Immunomodulatory and therapeutic properties of the Nigella sativa L. seed. International Immunopharmacology, 5: 1749-1770

32. Solomons K, Cochrane JW (1984) Formaldehyde toxicity. Part II. Review of acute and chronic effects on health. S Afr Med J, 66: 103-106.

33. Suryavanshi VL, Sathe PA, Baing MM, Singh GR, Lakshmi SN (2007) Determination of Rutin in Amaranthus spinosus Linn. Whole Plant Powder by HPTLC. Int Immunopharmacol, 5: 1749-1770.

34. Tang $X Q$, Ren $Y K$, Chen RQ, Zhuang $Y Y$, Fang $H R$, Xu JH, Wang CY, Hu B (2011) Formaldehyde induces neurotoxicity to PC1 2 cells involving inhibition of paraoxonase-1 expression and activity. Clin Exp Pharmacol Physiol, 38: 208-214.

35. Tanko Y, Mohammed A, Okasha MA, Shuaibu A, Magaji MG, Yaro AH (2007) Analgesic and anti-inflammatory activities of ethanol seed extract of Nigella sativa (black cumin) inmice and rats. Eur J Sci Res, 18: 277-281.

36. Tseng SC, Li DQ (1996) Comparison of protein kinase C subtype expression between normal and aniridic human ocular surfaces: implications for limbal cell dysfunction in aniridia. Cornea, 15: 168-178.

37. Welge-Lussen, U, May CA, Neubauer AS, Priglinger $S$ (2001) Role of tissue growth factors in aqueous humor homestasis. Curr Opin Ophthalmol, 12: 94-99.

38. West-Mays JA, Dwivedi DJ (2006) The keratocyte: corneal stromal cell with variable repair phenotypes. Int J Biochem Cell Biol, 38: 1625-1631.

39. Zwart A, Woutersen RA, Wilmer JW, Spit BJ, Feron VJ (1988) Cytotoxic and adaptive effects in rat nasal epithelium after 3-day and 13-week exposure to low concentrations of formaldehyde vapour. Toxicology, 51: 87-99. 